\title{
Inclination to self-ignition and analysis of gaseous products of wood chips heating
}

\author{
Michaela Skrizovska, Hana Veznikova, Petra Roupcova \\ VSB - TU Ostrava, Faculty of Safety Engineering, Lumirova 13, 70030 Ostrava - Vyskovice \\ michaela.skrizovska@vsb.cz
}

\begin{abstract}
This paper focuses on the assessment of the inclination to self-ignition of various types of wood chips according to the methodology of European standard EN 15188. The study also assesses the effect of heating temperatures on the composition and quantity of gaseous products of heating. Gases were analysed using an infrared spectrometer with Fourier transformation. From the measured results it was found that the inclination to self-ignition differs for various samples of wood chips. The paper discusses certain parameters assumed to affect the inclination of biomass to self-ignite. When assessing the effect of temperature on the composition of gaseous products, a sample of forest wood chips heated at temperatures from 50 to $150{ }^{\circ} \mathrm{C}$ resulted in the following gaseous products: carbon dioxide, carbon monoxide, water and aliphatic hydrocarbons; their concentrations increase with the increasing temperature. Carbon oxides have been proposed as indicators of the state of stored materials self-heating. Observations presented in this paper can be used as data for elaborating safety instructions for storage of fuels based on solid biomass.
\end{abstract}

Keywords: gaseous products, induction time, spontaneous combustion, self-heating temperature, wood chips.

\section{Introduction}

One of the possible alternatives to fossil fuels is the use of solid biofuels whose combustion causes less damage to the environment. In the Czech Republic, the most common alternative used for energyproduction purposes is wood chips. Wood chips are defined as chipped wood biomass typically $5 \mathrm{~mm}$ to $50 \mathrm{~mm}$ in size, produced by mechanical cutting of wood using sharp tools, e.g. blades (CSN EN ISO 17225-4, 2015).

No heating or drying is used during their production and most of the original wood humidity is retained. The production process of other types of solid biofuels, such as pellets or briquettes, involves heating and therefore their biological activity is reduced (Alakoski et al., 2016). For this reason, wood chips have higher tendency to spontaneous self-heating than other types of biofuels.

Self-ignition occurs mainly if chips are stored in large quantities and over long periods of time. Safe storage time is determined not only by the size of the stored pile, but also by the type of biomass, storage, material humidity and homogeneity as well as by other parameters.

Conditions for safe storage of solid biofuels are mainly determined based on the results of laboratory tests (Veznikova, 2016). A number of methods are used for this purpose, with both empirical and theoretical foundations. Methods currently used to assess the risk of spontaneous combustion evaluate the solids behaviour under adiabatic, isoperibolic or isothermal conditions (Babrauskas, 2003).
For example, the isoperibolic method according to European standard EN 15188 sets procedures for determining the volume dependence of self-ignition temperature of combustible dusts or granular materials. After determining this dependence in laboratory conditions, an extrapolation is performed for the expected conditions during storage of the evaluated material. The standard method is often used to assess the risk of spontaneous combustion of biomass and to determine safe storage conditions (Ramirez et al., 2010; Jones et al., 2015).

One of the methods used to control the development of material self-ignition in warehouses is to monitor changes in the concentration of gases produced during the self-heating process. Dominant gases emitted during heating by wood include carbon dioxide, carbon monoxide and methane (Alakoski et al., 2016). The method indicating the state of self-heating based on the analysis of gaseous products from heating has been used for many years, especially for coal materials. As the study of Derychova et al. (2016) shows, majority of gaseous products from coal and biomass are qualitatively identical. Therefore, analysis of gaseous products can also be used in the indication of the temperature of stored biomass. However, the composition and quantity of these products is affected, just like the self-ignition temperature, by the material properties and storage conditions. Therefore, besides the evaluation of the inclination of various wood chips to self-ignition, this study also evaluates the impact of temperature on the composition and quantity of carbon monoxide, carbon dioxide and methane for one type of biomass. 
Tab. 1. Overview of studies on self-ignition.

\begin{tabular}{ll}
\hline Resolved issues & Source \\
\hline Self-ignition in general & (Balog, 1999; Kalousek, 1999; Adamus et al, 2007, \\
& Věžníková \& Adamus, 2007) \\
$\begin{array}{l}\text { Self-ignition of plant materials } \\
\text { Effect of composition on self-ignition temperature }\end{array}$ & (Ekopor, 1999) \\
Effect of temperature on self-ignition temperature & (Balog, 1999) \\
$\begin{array}{l}\text { Effect of grain size on self-ignition temperature } \\
\text { Effect of humidity on self-ignition temperature }\end{array}$ & (Jirjis, 1995) \\
$\begin{array}{l}\text { Effect of volume of accumulated material on self-ignition } \\
\text { temperature }\end{array}$ & (Jirjis, 2005) \\
$\begin{array}{l}\text { Methods for determining inclination to self-ignition } \\
\text { Issue of gaseous products released during wood material } \\
\text { self-heating }\end{array}$ & (Adamus, 2004; Bowes, 1984) \\
$\begin{array}{l}\text { Effect of temperature on the quantity of gaseous products } \\
\text { released during wood material self-heating }\end{array}$ & (Kuang et al, 2009; Yazdanpanah et al, 2014; Kuang et al, \\
$\begin{array}{l}\text { Effect of concentration of oxygen on the composition of } \\
\text { gaseous product al, 1987; Perdochova, 2014) } \\
\text { heating }\end{array}$ & (Perdochova et al., 2015) \\
\hline
\end{tabular}

Numerous experimental studies have focused on the issue of self-ignition. An overview of the most important studies in this field is provided in Tab. 1. The cited papers focus primarily on the issue of selfignition in general, self-ignition of plant material, evaluation of various phenomena on self-ignition temperature and on the effect of temperature on the composition of products of wood material selfheating.

The effect of wood material variability on the selfignition process has not been deeply studied, most probably because biomass has been combusted on an industrial scale for a relatively short time. The variability of wood material composition is greater than in case of other fuels (Vassilev et al., 2015) and it affects the properties and behaviour of the material during its combustion and storage. The effect of chemical composition and physical properties (granulometry and ash content) on flammability, explosibility and inclination to self-ignition has only recently been addressed (Torrent et al., 2016). Numerous other papers deal with the comparison of economic parameters of combusting coal or fuel oil and wood material (Esteban et al., 2016).

In this study, the inclination to self-ignition was evaluated for four various types of wood chips and the effect of temperature on the composition of gaseous products of heating forest wood chips was also studied. The aim of the paper was to determine the effect of the biomass type on the self-ignition process and on the change of the gaseous products composition with temperature for forest wood chips. Based on the results, suitable measures were proposed to prevent self-ignition as unified instructions for safe storage of wood material.

\section{Material and Methods}

\section{Tested materials}

The following samples were subjected to testing (Fig. 1):

- Sample No. 1 - wood chips from deciduous trees - wood chips and crushed wood fuel, water M45, ash A5.0 according to ČSN EN ISO 17225-1 (CSN EN ISO 17225-1, 2015).

- Sample No. 2 - wood-working (white) wood chips - wood chips and crushed wood fuel, water M45, ash A5.0 according to ČSN EN ISO 17225-1 (CSN EN ISO 17225-1, 2015).

- Sample No. 3 - forest wood chips - wood chips and crushed wood fuel, water M50, ash A10.0+ according to ČSN EN ISO 17225-1 (CSN EN ISO 17225-1, 2015).

- Sample No. 4 - wood chips from poplars sorted wood chips class B 1 according to C̆SN EN ISO 17225-4 (CSN EN ISO 17225-4, 2015).

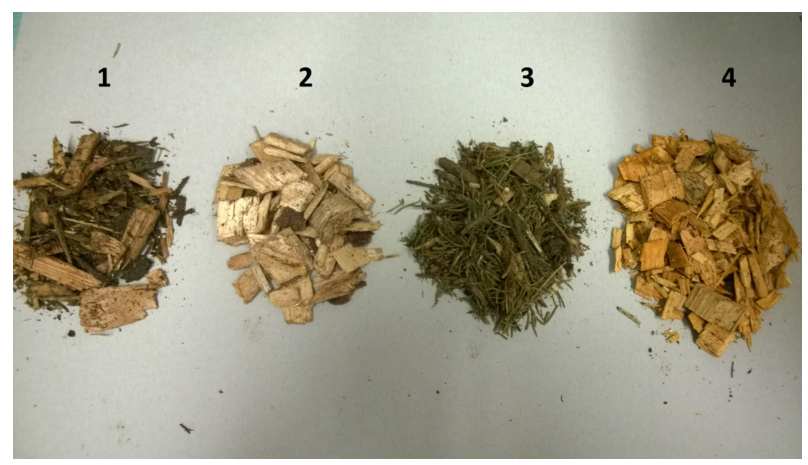

Fig. 1. Tested materials (Perdochova, 2015). 
Tab. 2. Proximate and ultimate analyses of samples.

\begin{tabular}{|c|c|c|c|c|}
\hline Properties/Tested material & $\begin{array}{l}\text { Deciduous wood } \\
\text { chips }\end{array}$ & $\begin{array}{c}\text { Wood-working wood } \\
\text { chips }\end{array}$ & $\begin{array}{c}\text { Forest wood } \\
\text { chips } \\
\end{array}$ & $\begin{array}{c}\text { Deciduous wood chips - } \\
\text { poplar }\end{array}$ \\
\hline \multicolumn{5}{|c|}{ Proximate analysis (wt \%) } \\
\hline $\operatorname{Ash} A^{d}$ & 4.66 & 3.95 & 11.90 & 2.86 \\
\hline Volatile combustible matter $\mathrm{V}^{\mathrm{daf}}$ & 82.93 & 83.38 & 81.10 & 85.07 \\
\hline Fixed carbon $\mathrm{C}_{\mathrm{f}}^{\mathrm{daf}}$ & 17.07 & 16.62 & 18.90 & 14.93 \\
\hline \multicolumn{5}{|c|}{ Ultimate analysis (wt \%) } \\
\hline Carbon total $\mathrm{C}_{\mathrm{t}}^{\mathrm{d}}$ & 49.34 & 49.54 & 46.89 & 49.44 \\
\hline Hydrogen total $\mathrm{H}_{\mathrm{t}}^{\mathrm{d}}$ & 5.46 & 5.55 & 5.14 & 5.54 \\
\hline Nitrogen $\mathrm{N}^{\mathrm{d}}$ & 0.18 & 0.09 & 0.34 & 0.16 \\
\hline Sulphur $\mathrm{S}_{\mathrm{t}}^{\mathrm{d}}$ & 0.04 & 0.03 & 0.04 & 0.03 \\
\hline Oxygen $\mathrm{O}_{\mathrm{d}}^{\mathrm{d}}$ (by calculation) & 44.98 & 44.79 & 47.59 & 44.83 \\
\hline
\end{tabular}

Note: meaning of symbols

Ash

Volatile combustible matter

Fixed carbon

Carbon total

Hydrogen total

Nitrogen

Sulphur

Oxygen (by calculation)
$\mathrm{A}^{\mathrm{d}} \quad$ Ash in dry matter

$\mathrm{V}^{\text {daf }} \quad$ Volatile combustible matter in dry ash-free basis

$\mathrm{C}_{\mathrm{f}}^{\mathrm{daf}}$ Fixed carbon (f) in dry ash-free basis

$\mathrm{C}_{\mathrm{t}}^{\mathrm{d}} \quad$ Carbon total in dry ash-free basis

$\mathrm{H}^{\mathrm{d}}{ }_{\mathrm{t}} \quad$ Hydrogen total in dry matter

$\mathrm{N}^{\mathrm{d}} \quad$ Nitrogen in dry matter

$\mathrm{S}_{\mathrm{t}}^{\mathrm{d}} \quad$ Sulphur in dry matter

$\mathrm{O}^{\mathrm{d}} \quad$ Oxygen (by calculation) in dry matter

Tab. 3. Summary of physical parameters of respective samples - moisture, apparent density, screen analysis (Perdochova, 2015).

\begin{tabular}{lcccc}
\hline Physical property & $\begin{array}{c}\text { Deciduous wood } \\
\text { chips }\end{array}$ & $\begin{array}{c}\text { Wood-working } \\
\text { wood chips }\end{array}$ & Forest wood chips & $\begin{array}{c}\text { Deciduous wood } \\
\text { chips - poplar }\end{array}$ \\
\hline Moisture $(\%)$ & 43.35 & 41.02 & 47.74 & 44.23 \\
Apparent density $\left(\mathrm{kg} \cdot \mathrm{m}^{-3}\right)$ & 330 & 280 & 320 & 300 \\
Mean grain size $(\mathrm{mm})$ & 8.88 & 13.23 & 8.75 & 9.40 \\
\hline
\end{tabular}

The aforementioned materials were sampled from a power company in the Czech Republic, which is one of the most significant consumers utilising renewable sources in large quantities.

Proximate and ultimate analyses were performed for all the tested samples - Tab. 2.

Tab. 3 shows measured values of the physical properties for the respective tested samples.

\section{Experimental methods}

Sampling was done according to standard ČSN EN 14778 - Solid biofuels - Sampling (CSN EN 14778, 2011). A total of four varieties of wood chips were sampled (four combined samples). According to standard ČSN EN 14780 - Solid biofuels - Methods for sample preparation (CSN EN 14780, 2011), subsamples were taken from the samples, for which the moisture content was determined immediately using a METTLER TOLEDO HS 153 halogen moisture analyser.

Furthermore, the subsamples were subject to proximate and ultimate analyses, apparent den- sity according to tandard ČSN EN 15103 - Solid biofuels - Determining apparent density (CSN EN 15103, 2010) and screen analysis according to standard C̆SN EN 933-1 - Testing of geometric properties of aggregates - Part 1: Determining granularity - Screen analysis (CSN EN 933-1, 2012).

Inclination to self-ignition, the so-called basket test, was determined for all combined samples using the method according to standard C.SN EN 15188 - Determination of the spontaneous ignition behaviour of dust accumulations (CSN EN 15188, 2008). This method is used to determine self-ignition temperature in relation to quantity based on piling in a furnace at a constant temperature. In addition, the induction period, defined by the standard as the period between reaching the storage temperature and ignition, was monitored.

The self-ignition temperatures were measured in a furnace for solid materials self-heating CLASIC CZ KK5006 (Czech Republic) with the volume of 
$54 \mathrm{dm}^{3}$. A special device for hanging a cubic basket with a sample and three thermocouples is installed in the test furnace. The furnace temperature is measured by two thermocouples placed in the middle of the distance between the furnace wall and the basket. The temperature of the sample is measured in the centre of the cubic basket with another thermocouple. The measurement takes place in the isoperibolic mode.

The first furnace test temperature was chosen according to the experience with the evaluated material. Once the selected temperature was reached, the sample basket with the sample was placed in the oven. The thermocouple located in the centre of the sample was used to indicate whether selfignition has occurred at the constant furnace temperature. Temperature for the next test is governed by the result of the previous test. The self-ignition temperature $\left(T_{S I}\right)$ was calculated as the temperature average of the two thermocouples that measure the temperature in the furnace.

Furthermore, in case of forest wood chips, gases were analysed in relation to temperature. The analysis of gaseous products was done using a NICOLET iS10 infrared spectrometer with Fourier transformation (USA).

After the measurements, the measured data of the respective samples were compared and evaluated in terms of fire due to self-ignition. Besides determining the self-ignition temperature, critical sample dimensions were also calculated, which characterise the degree of self-ignition risk at an ambient temperature and also the time in which self-ignition can occur at the given temperature and size. Based on the gas analysis, the effect of temperature on the composition and quantity of the gases produced during forest wood chips selfheating was evaluated.

\section{Analysis of gaseous products from forest wood chips} The apparatus used for the analysis of gaseous products of the forest wood chips self-heating was built from the following parts: furnace for solid materials self-heating with selectable atmosphere CLASIC CZ KK5006 (CR), NICOLET iS 10 infrared spectrometer with Fourier transformation (FTIR spectrometer- USA) equipped with a gaseous cuvette of the optical length of $10 \mathrm{~m}$, a pump and a computer. Samples of forest wood chips were heated at $50{ }^{\circ} \mathrm{C}, 100^{\circ} \mathrm{C}$ and $150^{\circ} \mathrm{C}$ in a cubic wire basket with the side dimensions of $7 \mathrm{~cm}$ for 1 hour. The gaseous products were identified using the OMNIC 8 software, and quantitative determination of carbon oxides and methane was done using the TQ Analyst spectroscopic software.

\section{Results and discussion}

\section{Determination of self-ignition temperature}

According to standard C̆SN EN 15188 (CSN EN 15188, 2008), the measured temperature-time relation is used to determine the self-ignition temperature, $T_{S I}$, for each basket volume. Cubeshaped baskets are used for the measurement. Furthermore, the measured results can be used to determine the induction burning period for various volumes. Table 4 shows results of the basket test of the tested samples; the given values are averages from two measurements. From the results it follows that with the increasing material volume, the selfignition temperature decreases and the induction period is extended.

Tab. 4. Results of the basket test (Perdochova, 2015).

\begin{tabular}{lccc}
\hline Tested sample & $\begin{array}{c}\text { Basket volume } \\
\left(\mathbf{c m}^{3}\right)\end{array}$ & $\begin{array}{c}\boldsymbol{T}_{\text {SI }} \\
\left({ }^{\circ} \mathbf{C}\right)\end{array}$ & $\begin{array}{c}\text { ID } \\
(\text { hour })\end{array}$ \\
\hline Deciduous wood & 343 & 204 & 2.17 \\
chips & 1000 & 183 & 3.20 \\
& 3375 & 160 & 4.90 \\
\hline Wood-working wood & 343 & 211 & 1.23 \\
chips & 1000 & 205 & 1.50 \\
& 3375 & 195 & 1.90 \\
\hline Forest wood chips & 343 & 193 & 1.33 \\
& 1000 & 177 & 2.83 \\
& 3375 & 160 & 6.23 \\
\hline Deciduous wood & 343 & 207 & 0.93 \\
chips - poplar & 1000 & 187 & 2.29 \\
& 3375 & 167 & 6.54 \\
\hline
\end{tabular}

Evaluation of the test results of self-ignition temperature determination was performed using the dependence of the logarithm of volume to surface ratio for the respective shape and site of the basket used $(\log [V / A])$ and the inverted reciprocal value of the self-ignition temperature $\left(1 / T_{S I}\left[\mathrm{~K}^{-1}\right]\right)$, known as the pseudo-Arrhenius graph of self-ignition temperature.

Equation (1) was used for the extrapolation of data outside the zone of measured temperatures and dimensions is as follows (CSN EN 15188, 2008):

$$
\log (V / A)=a+b \times\left(1 / T_{S I}\right)
$$

where $V$ - volume of precisely defined body $\left(\mathrm{m}^{3}\right)$, $A-$ surface of precisely defined body $\left(\mathrm{m}^{2}\right), T_{S I}-$ self-ignition temperature $(\mathrm{K})$.

The results obtained from Equation (1), i.e. logarithm of volume to surface ratio, are shown in Fig. 2. This Figure shows self-ignition temperatures (upper side of the graph) for different volumes of the material depending on $(\log (V / A)$ to $1 / T)$. 


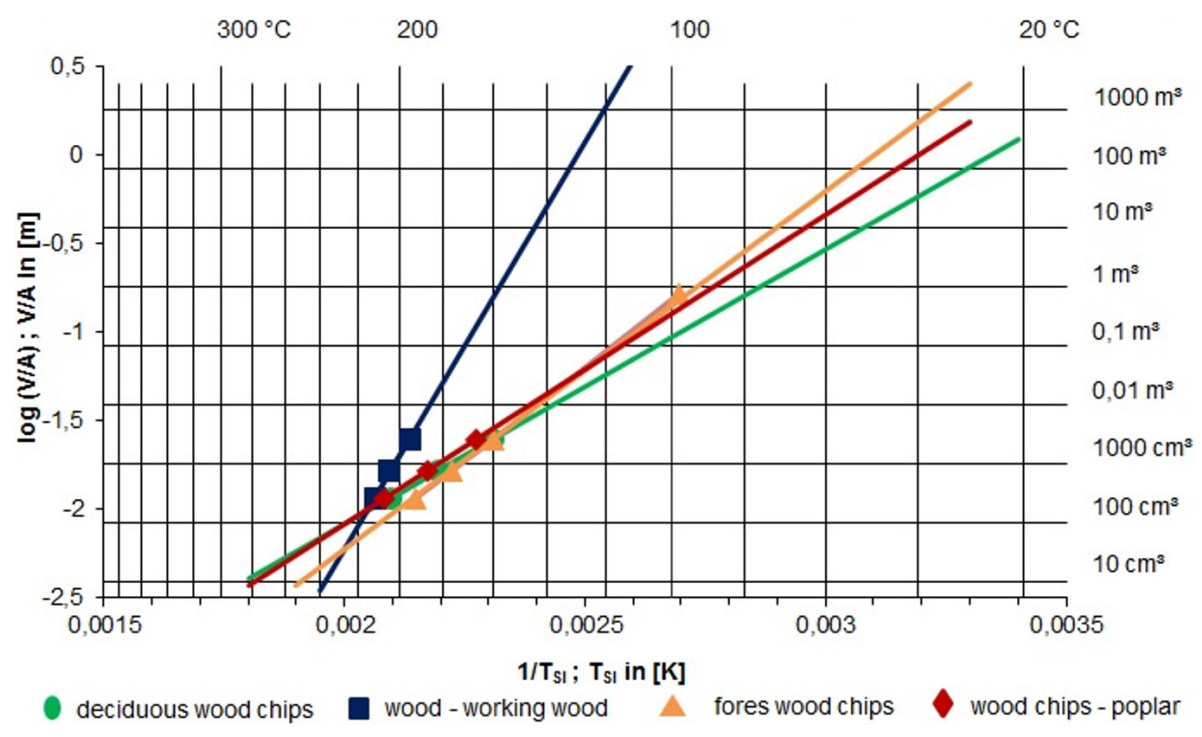

Fig. 2. Pseudo-Arrhenius graph of self-ignition temperature for tested samples (Perdochova, 2015).

From the graph above it is evident that samples of deciduous, forest wood chips and poplar have a similar course, whereas the dependence for wood-working wood chips is different. In case of wood-working wood chips, the intensity of oxidation is more strongly dependent on temperature than in case of the other samples, which can be due to different ingredients and structure. Based on this graph, self-ignition temperature $T_{S I}$ of woodworking wood chips is less dependent on the change of volume than in other materials. Wood-working wood chips are less prone to self-ignition than other types because of their higher self-ignition temperatures compared to other samples.

In addition, the logarithmic dependence of woodworking wood chips does not describe the course of the measured data as accurately as for other materials. Therefore, other types of mathematical expressions were tested and a third-degree polynomial was found applicable for wood-working wood chips. However, confirmation of the correctness using other experiments is necessary, at least for the $2000 \mathrm{~cm}^{3}$ basket volume.

The different dependence for wood-working wood chips may be due to the different properties of this material as wood working wood chips are made from wood free of bark, leaves or needles and therefore have lower nitrogen content (see Table 2) than the other samples. Nitrogen content is related to the presence of needles and leaves in the biomass (Blomqvist \& Persson, 2003) and can affect the course of self-heating, as these materials have lower ignition temperature $\left(270-3500^{\circ} \mathrm{C}\right)$ than wood $\left(410-450{ }^{\circ} \mathrm{C}\right)$ (Babrauskas, 2003).

Another possible cause of the different behaviour of wood-working wood chips is the grain size, which is different than in the other samples. In case of wood-working wood chips, the mean grain size was about $13 \mathrm{~mm}$, whereas in the other samples it was around $9 \mathrm{~mm}$. According to literature (Jirjis, 1995), the increased size of particles means a decreasing risk of self-ignition, which has been confirmed by the self-ignition temperature measurement (woodworking wood chips have the lowest inclination to self-ignition).

The graph in Fig. 3 shows that the dependence of the volume to surface ratio logarithm on temperature also differs for different samples (other than woodworking wood chips). For small sample volumes, forest wood chips are most easily self-ignited, whereas the lowest inclination to self-ignition is demonstrated by wood-working wood chips. However, during extrapolation to larger volumes, deciduous wood chips, which contained bark just like forest wood chips, were shown to be more inclined to self-ignition.

Also, induction time of combustion for various volumes as a dependence of the induction time logarithm $\left(t_{i}\right)$ to the volume to surface ratio logarithm for a given shape and size of the used basket $(\log [V / A])$ can be determined from the measured results (Fig. 3). The induction time is designed by the standard C̆SN EN 15188 (CSN EN 15188, 2008) as a period between reaching storage temperature and ignition. The determined dependence is described by Equation (2):

$$
\log \left(t_{\mathrm{i}}\right)=a \times \log (V / A)-b
$$

where $t_{\mathrm{i}}$ - induction time (h), $V$ - volume of precisely defined body $\left(\mathrm{m}^{3}\right), A$ - surface of precisely defined body $\left(\mathrm{m}^{2}\right)$.

Graph 3 shows the induction time, $t_{i}$, required to reach the self-ignition temperature, $T_{s i}$, under opti- 


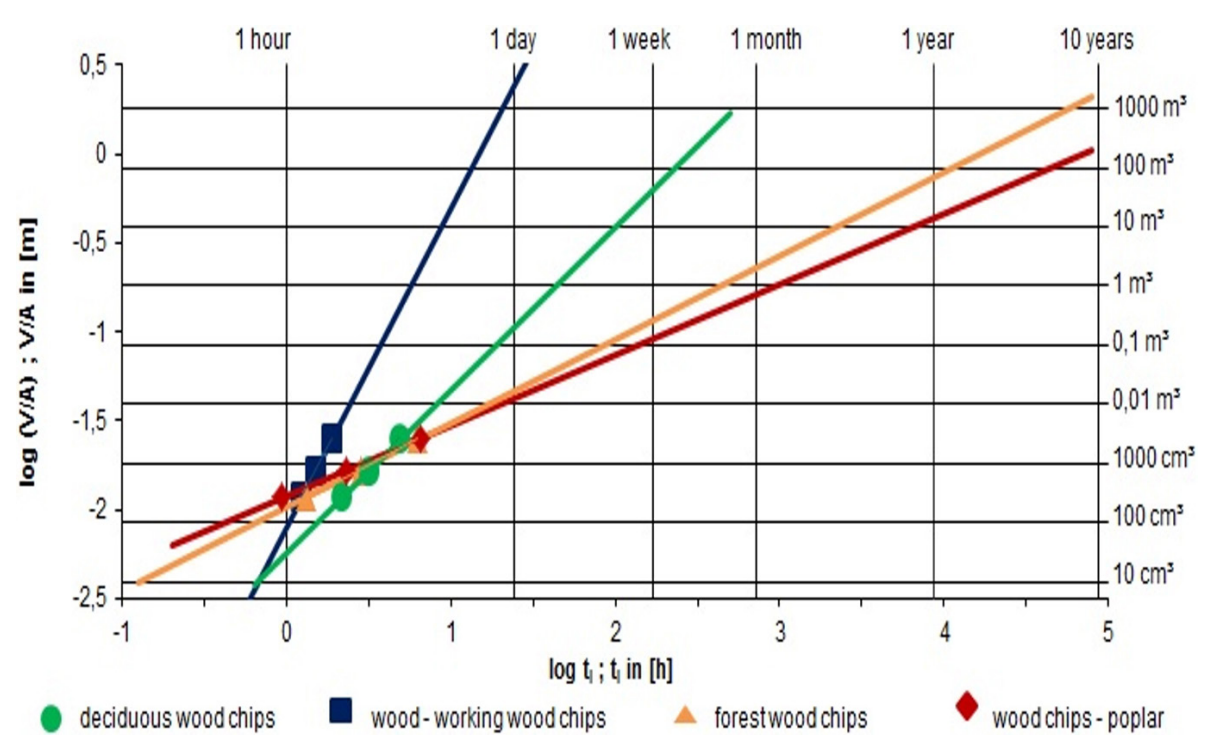

Fig. 3. Dependence of induction time on the volume to surface ratio of the tested samples (Perdochova, 2015).

mal condition for the advancement of self-heating at a given volume to surface ratio, $V / A$.

The dependence of induction time on the self-ignition temperature has an approximately linear character. This dependence is described by Equation (3):

$$
t_{\mathrm{i}}=-0.0961 T_{S I}+20.932
$$

Its coefficient of determination $\mathrm{R}^{2}=0.8161$ indicates strong dependence of the induction time on temperature. Therefore, samples of materials (deciduous wood chips - green line, wood-working wood chips - blue line) with higher self-ignition temperature behave differently.

From the above graphs (Figs. 2 and 3), self-ignition temperatures and times necessary for the selfignition of samples for volumes approximating the realistic storage of the tested materials, i.e. for larger volumes, can be estimated. For example, wood-working wood chips with the cubic volume of $1 \mathrm{~m}^{3}$ self-ignite above $98^{\circ} \mathrm{C}$ (Fig. 2). If this sample is stored at this constant temperature, a fire would start after 15.4 days (Fig. 3).

After modification, the extrapolated dependence also provided critical dimensions of stored dust for the respective samples, which presents a risk of selfignition at the given ambient temperature, and also the time after which self-ignition can occur at the respective temperature and dimensions; characteristic dimensions, i.e. the cube's side, which are limiting for the self-ignition. These dependencies can also be used to evaluate the danger of layers of deposited dust at higher temperatures. According to the calculated values, a deciduous wood chips pile of about $5.17 \mathrm{~m}$ would self-ignite after being stored for about 9.78 days at $30{ }^{\circ} \mathrm{C}$. From this evaluation it follows that under normal conditions it is highly probable that storage of deciduous wood chips can lead to self-ignition. If this stored material is heated to an even higher temperature, the risk of fire increases. Therefore, to prevent self-ignition, the stored material must be protected against sources of heat and by increasing its surface area. Self-ignition is also probable in case of poplar and forest wood chips because they can self-ignite at $30^{\circ} \mathrm{C}$ and dimensions of $9.31 \mathrm{~m}$ (poplar) and $15.07 \mathrm{~m}$ (forest wood chips). Compared to that, wood-working wood chips under normal conditions are improbable to self-ignite during storage because the calculated layer height at which self-ignition could occur at around $30{ }^{\circ} \mathrm{C}$ exceeds realistic storage conditions.

\section{Effect of temperature on the composition of gaseous products of forest wood chips}

Fig. 4 shows an example of infrared spectra of gaseous product composition for forest wood chips at 50,100 and $150{ }^{\circ} \mathrm{C}$ in the $60^{\text {th }}$ minute from the measurement start.

Spectral analysis has shown that at temperatures of 50, 100 and $150{ }^{\circ} \mathrm{C}$, carbon oxides, water and aliphatic hydrocarbons are produced. In all cases, water demonstrated the highest intensity in the $4000-3500 \mathrm{~cm}^{-1}$ and $1700-1300 \mathrm{~cm}^{-1}$ zones, followed by carbon dioxide in the $2350 \mathrm{~cm}^{-1}$ and $670 \mathrm{~cm}^{-1}$ zones. Carbon monoxide, which is found immediately next to carbon dioxide, lies in the $2240-2040 \mathrm{~cm}^{-1}$ zone. In case of the sample tested at $150{ }^{\circ} \mathrm{C}$, the presence of carbon monoxide was evident, whereas for samples heated at lower temperatures, only its traces are shown in the spectrum throughout the entire sample heating time. During wood chips heating, a clear band appeared in the $3000-2800 \mathrm{~cm}^{-1}$ zone indicating the presence of 


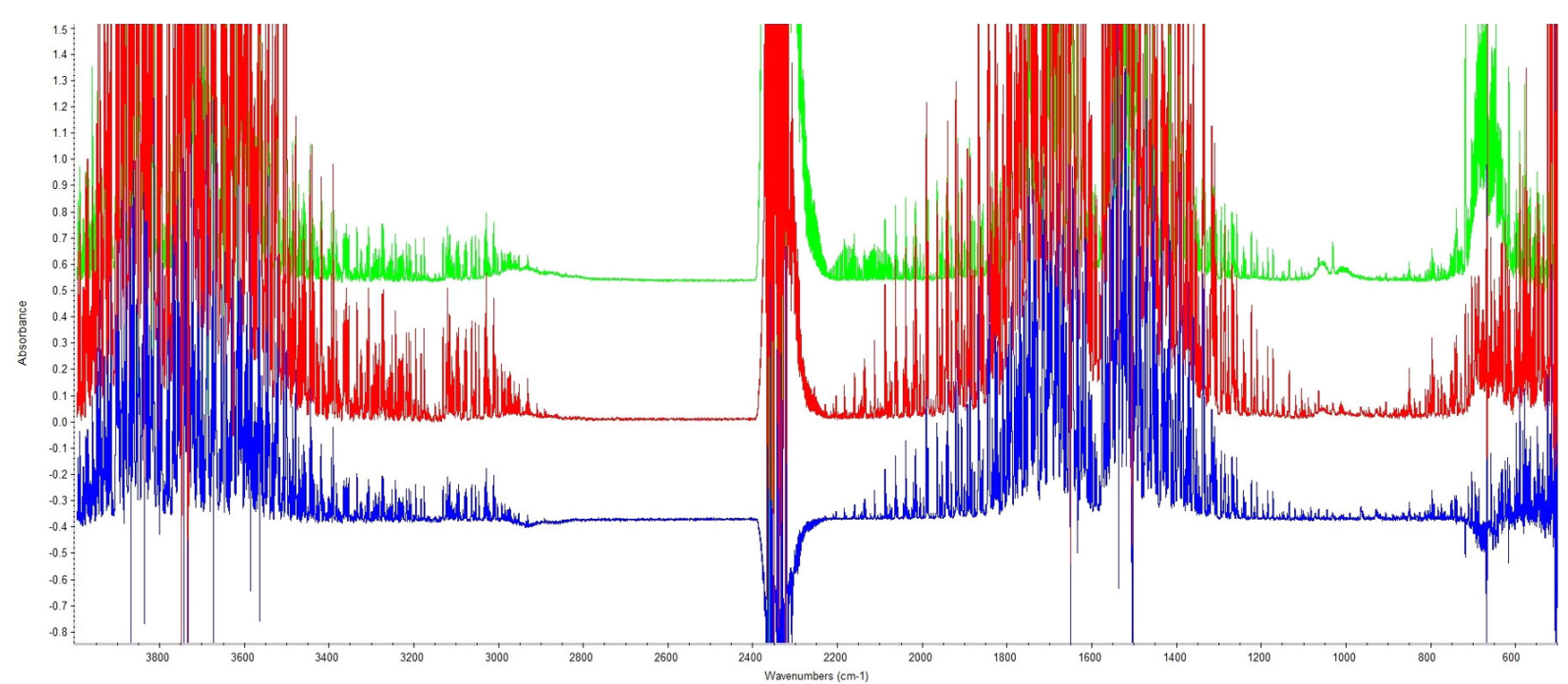

Fig. 4. Infrared spectrum of gaseous products produced by decomposition of forest wood chips at 50 (blue spetrum), 100 (red spectrum) and $150^{\circ} \mathrm{C}$ (green spectrum) in the $60^{\text {th }}$ minute.

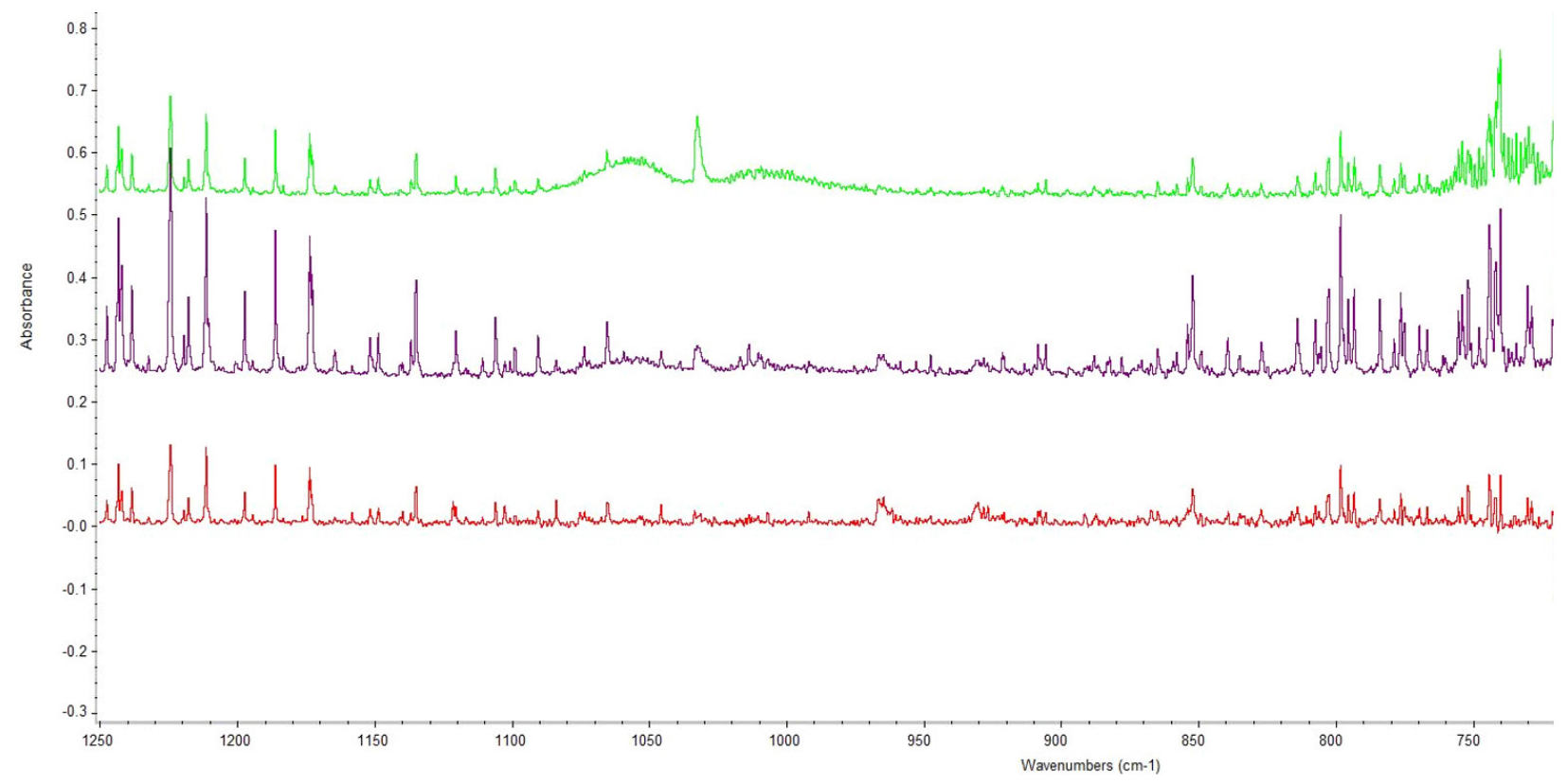

Fig. 5. Band of methanol in the spectrum of gaseous products of forest wood chips decomposition at 150 (green spectrum), 100 (purple spectrum) and $50^{\circ} \mathrm{C}$ (red spectrum).

aliphatic hydrocarbons. Aliphatic hydrocarbons also have a band in the $1450-1300 \mathrm{~cm}^{-1}$ zone, which however also includes a water absorption band; therefore, their presence could not be confirmed. When heating forest wood chips to $150^{\circ} \mathrm{C}$, methanol was detected in the gaseous products, with a band in the $1100-960 \mathrm{~cm}^{-1}$ zone which has a significant peak at $1030 \mathrm{~cm}^{-1}$ (see green spectrum in Fig. 5) and a band around $3100 \mathrm{~cm}^{-1}$. Here, it is necessary to emphasize that methanol, just like carbon monoxide, is a toxic substance.

As it is evident from the spectra above, heating temperature affects the composition of gaseous products. At higher temperatures, more harmful substances are released and it is therefore necessary to monitor the temperature of the stored material to prevent self-ignition and the occurrence of hazardous substances.

\section{Effect of temperature on $\mathrm{CO}_{2}, \mathrm{CO}$ and $\mathrm{CH}_{4}$ concentrations in forest wood chips}

The effect of heating temperature on the concentration of $\mathrm{CO}_{2}, \mathrm{CO}$ and $\mathrm{CH}_{4}$ was evaluated and the changes in the concentrations of these gases at $50-150{ }^{\circ} \mathrm{C}$ for forest wood chips are shown in Tab. 5 .

From Table 5 it is evident that the heating temperature affects the quantity of the produced gases. For 
Tab. 5. Time-dependent concentrations of $\mathrm{CO}_{2}, \mathrm{CO}$ and $\mathrm{CH}_{4}$ in forest wood chips at different temperatures.

\begin{tabular}{rrrrrrrrrr}
\hline & \multicolumn{3}{c}{$\begin{array}{c}\mathbf{C O}_{2} \text { concentration } \\
(\mathbf{p p m})\end{array}$} & \multicolumn{3}{c}{$\begin{array}{c}\text { CO concentration } \\
(\mathbf{p p m})\end{array}$} & \multicolumn{3}{c}{$\begin{array}{c}\mathbf{C H}_{4} \text { concentration } \\
(\mathbf{p p m})\end{array}$} \\
\hline $\begin{array}{r}\text { Time } \\
(\mathbf{m i n})\end{array}$ & $\mathbf{5 0}{ }^{\circ} \mathbf{C}$ & $\mathbf{1 0 0}{ }^{\circ} \mathbf{C}$ & $\mathbf{1 5 0}{ }^{\circ} \mathbf{C}$ & $\mathbf{5 0}{ }^{\circ} \mathbf{C}$ & $\mathbf{1 0 0}{ }^{\circ} \mathbf{C}$ & $\mathbf{1 5 0}{ }^{\circ} \mathbf{C}$ & $\mathbf{5} 0{ }^{\circ} \mathbf{C}$ & $\mathbf{1 0 0}{ }^{\circ} \mathbf{C}$ & $\mathbf{1 5 0}{ }^{\circ} \mathbf{C}$ \\
\hline 0 & 19.74 & 2117.08 & 19567.00 & 3.32 & 8.79 & 139.86 & 19.31 & 39.03 & 82.31 \\
10 & 24.28 & 1610.67 & 11300.74 & 2.88 & 10.51 & 124.60 & 16.79 & 43.35 & 78.83 \\
20 & 23.65 & 944.44 & 4711.99 & 3.81 & 10.10 & 119.00 & 11.59 & 42.48 & 64.74 \\
30 & 21.16 & 490.87 & 3666.46 & 4.29 & 8.62 & 110.88 & 8.70 & 38.85 & 75.41 \\
40 & 19.48 & 186.66 & 3064.21 & 3.31 & 8.99 & 98.05 & 10.82 & 42.99 & 62.95 \\
50 & 18.05 & 53.00 & 2767.79 & 3.50 & 11.27 & 85.14 & 9.42 & 42.64 & 56.49 \\
60 & 12.00 & 28.00 & 2772.60 & 3.01 & 8.15 & 87.7 & 9.13 & 45.53 & 56.49 \\
\hline Average & $\mathbf{1 9 . 7 7}$ & $\mathbf{7 7 5 . 8 2}$ & $\mathbf{6 8 3 5 . 8 3}$ & $\mathbf{3 . 4 5}$ & $\mathbf{9 . 4 9}$ & $\mathbf{1 0 9 . 3 2}$ & $\mathbf{1 2 . 2 5}$ & $\mathbf{4 2 . 1 2}$ & $\mathbf{6 8 . 1 7}$ \\
\hline
\end{tabular}

all tested gases applies that increasing temperatures increases the gas concentration. At $150{ }^{\circ} \mathrm{C}$, the increase of gas concentration is very sharp for carbon oxides, whereas in case of methane, the increase already occurs at $100^{\circ} \mathrm{C}$ and a further increase in temperature does not lead to such a sharp increase in the concentration as in case of carbon oxides. Therefore, it can be concluded that the reaction mechanism of carbon oxide production is different to that of methane.

During wood chips heating, the highest volume of released gases was found for carbon dioxide even though the volume of methane at $50{ }^{\circ} \mathrm{C}$ was comparable.

Thus, the heating temperature affects the quantity of gases produced by wood material decomposition and the carbon dioxide and methane concentration can be used as indicators of self-ignition development. It is generally known that these gases are used for the indication of self-ignition in coal. Nevertheless, based on the difference of gases concentrations at various temperatures, it is necessary to consider which gas is most suitable as the indicator of self-ignition state.

Also, the $\mathrm{CO} / \mathrm{CO}_{2}$ ratio (Adamus et al, 2007) is often used as an indicator of the stored material temperature. Nonetheless, Derychová et al. (2016) stated that the use of the $\mathrm{CO} / \mathrm{CO}_{2}$ concentration ratio to estimate the temperature of wood material, especially saw dust, is not possible. In addition, in case of forest wood chips evaluated in this study, the $\mathrm{CO} / \mathrm{CO}_{2}$ ratio cannot be used to indicate the temperature increase.

With respect to the safety of workers, carbon monoxide should be used as the indicator of self-ignition due to its toxicity. However, because the differences in concentrations at various temperatures are more distinct for carbon dioxide, its production has also to be monitored in addition to carbon monoxide, using it to more accurately monitor the early stages of self-ignition.

An intervention upon the increase of the measured gases concentration can serve as a measure against the initiation of fire due to the self-ignition of stored wood material.

The measurements and evaluated data lead to the following conclusions:

- The lowest inclination to self-ignition is demonstrated by wood-working wood chips. It was found that at small volumes, forest wood chips are most inclined to self-ignition, but after extrapolation to larger volumes, deciduous wood chips have proved to be more prone to self-ignition.

- In case of wood-working wood chips, a different trend of dependence was observed than for the remaining tested samples, which is probably due to the absence of bark, leaves or needles in the sample as well as different particle size.

- Qualitative analysis of gaseous products of forest wood chips showed that carbon oxides, water and aliphatic hydrocarbons are produced at $50,100,150{ }^{\circ} \mathrm{C}$. When heating forest wood chips to $150^{\circ} \mathrm{C}$, methanol was also detected in the gaseous products.

- Concentrations of carbon dioxide, carbon monoxide and methane increase with the increasing temperature.

- Carbon oxides and methane can be considered as characteristic gases for the indication of wood chips self-heating.

\section{Conclusion}

This study focuses on the evaluation of the inclination to self-ignition and the effect of heating temperature on gaseous products for various types of wood chips with the aim to compare their behaviour at increased temperatures, and thereby to obtain 
objective data for the proposal of suitable measures to prevent self-ignition.

Measurement results showed that the inclination to self-ignition is not the same for all types of wood chips. Besides the self-ignition temperature for the respective volumes, which were different for each sample, the character of the dependence between the self-ignition temperature and biomass volume also differed.

Three of the evaluated samples demonstrated a strong inclination to self-ignition. The sample of wood-working wood chips showed differences compared to the other samples. This wood chip type demonstrated the lowest inclination to selfignition, so its self-ignition is very improbable. Its low inclination to self-ignition is probably due to the low content of bark, leaves and needles in the sample, which was also demonstrated by the low nitrogen content.

Furthermore, it was found that the heating temperature affects the gases released from the forest wood chips. Gaseous products of heating are comprised mainly of water vapour, carbon oxides and aliphatic hydrocarbons. At the highest heating temperature, methanol was also released. The heating temperature also affects the amount of monitored gases. Higher concentrations were measured with increasing temperature.

The performed measurements showed that selfheating of biomass based on wood material stored in large quantities can lead to a fire. During selfheating, production of toxic gases occurs compromising safety at the worksite in case of storage in closed areas.

From the above it follows that for safe storage of wood material, no universal instructions can be drawn. Each company should elaborate its own instructions for the specific type of biomass and situation regarding the storage of biomass in terms of self-ignition.

For each type of biomass, the instructions should include the maximum storage height of loosely dumped piles and the maximum time of storage. These safety parameters can be determined experimentally. Verification of the course of self-ignition can be done by analysing the carbon dioxide and carbon monoxide released from the stored wood chips.

\footnotetext{
Acknowledgement

This article was written in the framework of the project "Innovation of the Subject Transport of Hazardous Substances and Waste". Project number: RPP2020/131 funded by the University Development Fund (FRVŚ) of the Ministry of Education, Youth and Sports of the Czech Republic.
}

\section{References}

Adamus A (2004) Collection of scientific works of Vysoká škola báňská - Technical University of Ostrava, Mining-geological series 50.

Adamus A, Věžníková H, Šancer J (2007) Coal, ore, geological survey: 31-37.

Alakoski E, Jämsén M, Agar D, Tampio E, Wihersaari M (2016) Renewable and Sustainable Energy Reviews 54: 376-383.

Babrauskas V (2003) Ignition Handbook: Principles and applications to fire safety engineering, fire investigation, risk management and forensic science. Fire Science Publishers, USA.

Balog K (1999) Self-ignition. SPBI, Ostrava.

Blomqvist P, Persoon B (2003) Spontaneous Ignition of Biofuels - A Literature Survey of Theoretical and Experimental Methods. Boras: SP Swedish National Testing and Forsknings institut Research Institute.

Bowes P (1984) Self-heating: evaluating and controlling the hazards. Dept. of the Environment, Building Research Establishment, Elsevier, Amsterdam.

CSN EN ISO 17225-1 (2015) Solid biofuels - Fuel specifications and classes - Part 1: General requirements. Czech Office for Standards, Metrology and Testing, Prague.

CSN EN ISO 17225-4 (2015) Solid biofuels - Fuel specifications and classes - Part 4: Graded wood chips. Czech Office for Standards, Metrology and Testing, Prague.

CSN EN 15188 (2008) Determination of the spontaneous ignition behaviour of dust accumulations. Czech Normalization Institute, Prague.

CSN EN 14778 (2011) Solid biofuels - Sampling. Czech Office for Standards, Metrology and Testing, Prague.

CSN EN 14780 (2011) Solid biofuels - Sample preparation. Czech Office for Standards, Metrology and Testing, Prague.

CSN EN 15103 (2010) Solid biofuels - Determination of bulk density. Czech Office for Standards, Metrology and Testing, Prague.

CSN EN 933-1 (2012) Tests for geometrical properties of aggregates - Part 1: Determination of particle size distribution - Sieving method. Czech Office for Standards, Metrology and Testing, Prague.

Derychova K, Perdochova M, Veznikova H, Bernatik A (2016) Journal of Loss Prevention in the Process Industries 43: 203-211.

Ekoporadna (2010) Why use biomass for heating? Available at: http://www.ekoporadna.cz/wiki/doku. php?id=energie:proc_topit_biomasou.

Esteban B, Riba JR, Baquero G, Rius A (2015) Renewable Energy 74: 568-575.

He X, Lau AK, Sokhansanj S, Lim CJ, Bi XT, Melin S (2014) Fuel 134: 159-165.

Jäppinen E, Korpinen OJ, Laitila J, Ranta T (2014) Renewable and Sustainable Energy Reviews 29: 369-382.

Jirjis R (1995) Biomass and Bioenergy 9: 181-190.

Jirjis R (2005) Biomass and Bioenergy 28: 193-201.

Kalousek J (1999) Basics of physical chemistry of combustion, explosion and extinguishing. SPBI, Ostrava. 
Kuang X, Shankar TJ, Bi XT, Sokhansanj S, Lim CJ Melin S (2008) Annals of Occupational Hygiene 52: $675-683$.

Kuang X, Shankar TJ, Bi XT, Lim CJ, Melin S (2009) Annals of Occupational Hygiene 53: 789-796.

Lohrer CH, Krause U, Steinbach J (2005) Process Safety and Environmental Protection 83: 145-150.

Oren MJ, Karunakaran KP, Pegg MJ, Mackay MD (1987) Fuel 66: 9-12.

Perdochova M (2014) Safety, reliability and risks 2014: XI. International Conference for Young Scientists. Liberec: Technical University of Liberec.

Perdochova M (2015) Post-graduate thesis, VŠB Technical University of Ostrava, Faculty of Safety Engineering.

Perdochova M, Derychova K, Veznikova H, Bernatik A, Pitt M (2015) Process Safety and Environmental Protection 94: 463-470.
Stuart BH (2004) Infrared Spectroscopy: Fundamentals and Applications. Chichester, UK: John Wiley \& Sons, Ltd.

Torrent JG, Gómez ÁR, Anez, NF, Pejic LM, Tascón A (2016) Fuel 184: 503-511.

Yazdanpanah F, Sokhansanj S, Lim CJ, Lau A, Bi X, Melin S (2014) Biomass and Bioenergy 71: 1-11.

Vassilev SV, Vassileva CHG, Vassilev VS (2015) Fuel 158: 330-350.

Věžníková H, Adamus A (2007) Coal - Ores - Geological survey 14: 32-36.

Veznikova H (2016) The self-heating of organic materials. SPBI, Ostrava.

Ramirez A, Garcia-Torrent J, Tascon A (2010) Journal of Hazardous Materials 175: 920-927.

Jones JM, Saddawi A, Dooley B, Mitchell EJS, Werner J, Waldron DJ, Weatherstone S, Williams A (2015) Fuel Processing Technology 134: 372-377. 